This PDF is a selection from an out-of-print volume from the National Bureau of Economic Research

Volume Title: The State of Monetary Economics

Volume Author/Editor: Universities-National Bureau Committee for Economic Research

Volume Publisher: NBER

Volume ISBN: 0-87014-307-7

Volume URL: http://www.nber.org/books/univ65-1

Publication Date: 1965

Chapter Title: Processes and Responses in Monetary Control

Chapter Author: G. L. Bach

Chapter URL: http://www.nber.org/chapters/c5182

Chapter pages in book: (p. 129 - 134) 


\title{
PROCESSES AND RESPONSES IN MONETARY CONTROL
}

\author{
G. L. Bach, Carnegie Institute of Technology
}

$\mathrm{W}$ HAT have we learned from the Commission on Money and Credit about processes and responses in monetary policy? So far as I can see, from the Report itself, very little - but perhaps experts in monetary economics were not a significant part of the audience at whom the Report was aimed. So the most fruitful course may be to turn primarily to the staff papers.

Here there is substantial evidence of the quantity theory reborn - at least in the sense that money matters a good deal in determining aggregate spending on current output and of an important postwar change in monetary theory. As noted in my introduction to this volume, this postwar shift in theory is centered in the "portfolio" approach to the demand for money and other assets. In this theory, the channels through which variations in the money supply affect the levels of income and employment include not only a change in "the interest rate" but also changes in relative prices of all assets - real and financial which in turn lead to shifts in spending on existing assets and currently produced goods and services. Thus in its extreme form the new approach suggests that we need to look not at one interest rate but at an extremely large number, including the implied interest rates on all real assets and including consumer goods of any degree of durability.

In logical terms, this approach offers an elegant rapprochement for the devotees of the "Keynesian" and the "quantity-theory" approaches to the role of money, and for the monetary-versus-fiscal policy disputes since the r930's. If the new look prevails, we may look back at much of this controversy as a good deal less significant than it has seemed en route. The great controversy over "Is savings really equal to investment?" of the late r930's and early r940's springs to mind.

But agreement on this mechanism doesn't necessarily tell us how important money is quantitatively. If we look at the staff papers (or at least, at the sample I managed), what does the professional support for the renais- sance of money and monetary policy amount to? Friedman and Meiselman, as might be expected, plump for money as a prime determinant of the level of spending on current output, and show convincingly that a simple, traditional monetary model versus a simple traditional Keynesian model test gives the verdict clearly to stability for velocity over stability for the ratio of autonomous investment to income, including cases where reasonable lags are introduced. Moreover, they go on to spell out the portfolio balancing mechanism as at least a plausible mechanism through which this monetary effect may be exerted. If we take Section VI of their paper as a statement of the "new monetary orthodoxy," on intellectual grounds at least a good deal of the basis for the long quarrel between the monetary and the Keynesian economists has been reasoned (or compromised) away. Few, even the most ardent neo-Keynesians, would disagree that the impact of open market operations may be through the spreading net which Friedman and Meiselman spell out not merely through one (bond) interest rate alone acting on "investment" decisions. The major challenge to the now generally accepted fiscal policy position as our really powerful stabilization tool becomes a strong one if a reasonably stable demand for money is added to the new mechanism - as at least Friedman and Meiselman argue. The C.M.C. staff papers contain no empirical answer to the Friedman and Meiselman challenge to show better results with another model.

Tobin, in his paper on debt policy, provides an elegant statement of a very similar mechanism through which changes in the money stock and liquidity may influence spending decisions on current output through the rebalancing of asset portfolios.

But I hope it will not be too dissident a note to suggest that we really know very little empirically about the validity of this description of the channels of monetary policy; and that the elaborate portfolio-balancing general equilibrium approach lacks intuitive appeal 
as a description of what most of us do in managing our own economic affairs, so that empirical validation becomes all the more important. Is it true that the interest rates that matter most include whole elaborate net of yields on assets in spreading the impact of more money? It would be reassuring if we had more behaviorial evidence at the micro level to confirm the over-all empirical support advanced by Friedman and others on the new channels of monetary policy.

The staff papers are not barren on empirical evidence of the actual channels. Brown, Solow, Ando, and Kareken attack the lag problem empirically, and intriguingly seem to end up confirming the usability of active monetary policy to a higher degree than Friedman does, since they assert that the lag is probably only about six months. The multiple authors of this paper are modest in their claims for their results, and I fear I must agree that the results call for such modesty. Leaving aside the now well-argued statistical issue on comparing rates of change against levels, the Brown, Solow, et al. case for the six-month lag could have been stretched a good deal either way without much implausibility. And, on what to me is an even more important issue - the variability of the lag - neither they nor anyone else in the staff papers pretends to throw much, if any, light except on purely a priori grounds. In my judgment the verdict has to be: result still uncertain on even average length of lags, and more evidence desperately needed on the critical issue of variability.

Modest empirical knowledge is added on channels of impact by Meltzer, Okun, Friend, and Bach, who trace the spread of restrictive policy through the banking and certain nonbank sectors of the economy, with the conclusion that such restriction does not distort seriously the otherwise established patterns of market relationships. Friend produces direct data that the nonbank financial intermediaries pose less of a problem to effective monetary policy than Shaw and Gurley and others have claimed. Okun shows that monetary policy seems to act effectively on certain interest rates, and produces quantitative estimates of the changes in rates attributable to specific policy changes on the basis of recent experi- ence. Brownlee and Conrad try to specify the channels through which alternative policies act in checking inflation and to quantify the results at different stages.

All this adds up to a good deal of support theoretically and empirically - for reestablishing a major role for money and monetary policy. But I have an uncomfortable feeling that the foundation is not happily solid yet; the parallel of the great intellectual faith in money during the prosperity of the I920's comes to mind. At the risk of sounding like a Monday morning quarterback, let me conclude by suggesting some questions the Commission's research directors might have asked and apparently did not.

(I) To what extent historically can we isolate cases where changes in the money supply were independent of the public's spending and output decisions? Given the agreed close correlation between the two, we need to establish whether changes in the money stock were really caused by changes in economic activity rather than vice versa. I suspect we may find that supply changes can be established as quite independent in many important cases, such as the big inflations and depressions, though much less clearly so in minor fluctuations. Cagan and Friedman may have these answers for us in their forthcoming volumes.

(2) To what extent can the monetary authorities actually control the stock of spendable money (currency and demand deposits) by controlling the total volume of currency and deposits, which is all they have within their proximate power through their control over reserves? Over long periods and with comparable interest rates, the relation of time deposits to total currency plus deposits looks pretty stable. But for short periods, the relationship obviously may be very unstable, as in recent years.

(3) Lastly, and perhaps most important, which model (in a sophisticated form that makes its proponents happy) really gives the best results - a basically "monetary" model or an "income-expenditures" model with money explicitly built in? Ultimately it is through development and careful testing of two or three more complex models against one 
another and against Friedman's models that we can hope to reach reasonable professional consensus on just how important money is and how it works on the major ultimate variables.
The new look in monetary theory is intellectually attractive. What we need most now is some more figures to flesh out the model.

\section{COMMENT}

WARREN SMITH, University of Michigan

The Report of the Commission on Money and Credit does not, in my judgment, fully deserve the caustic criticisms directed at it by Martin Bronfenbrenner in his paper. It is true that the Report is quite fuzzy in places and that the analysis not infrequently bears little relation to the ensuing recommendations. It deals inadequately with policy objectives and glosses over the difficulties arising out of conflicts between objectives, and it is wishy-washy on the balance-of-payments problem. But, in spite of its weaknesses, I believe it is a valuable document which contains many useful recommendations. I happen to agree with the philosophy underlying the Report on such matters as the need for greater executive discretion in fiscal policy and on the choice of the proper mix of monetary and fiscal policies.

Some of the recommendations relating to the relaxation of portfolio and interest-rate restrictions applicable to financial institutions would, I suspect, be accepted by practically everyone attending this conference. If adopted, these recommendations would increase efficiency in the allocation of capital and perhaps modestly strengthen monetary policy. Some of us would want to go further than the Commission does and allow commercial banks to pay interest on demand deposits.

It seems to me that it is much too early to judge the impact of the Report on economic policy - indeed it may never be possible to assess its impact with much precision. Its publication was undoubtedly a significant factor in encouraging the Kennedy Administration to put before Congress proposals for increasing the President's discretion in fiscal policy, proposals which parallel quite closely certain of the recommendations of the Commission. In addition, the President has ap- pointed three interagency working groups to follow up and appraise the Commission's proposals relating to ( $\mathrm{I}$ ) regulation of banks and other financial institutions, (2) federal lending and loan guarantee programs, and (3) private pension funds. Even if the recommendations of the Commission are not immediately adopted, it is quite possible that the Report may help to set in motion a process of reappraisal which will eventually produce some important changes.

\section{Processes and Responses in Monetary Policy} The conclusions concerning monetary policy do not appear to be based to any appreciable extent on new knowledge that was uncovered in the course of the study. The Commission surveyed the same ground that others of us have gone over, and it encountered the same difficulties. Since many of the issues are quite technical and since the Commission was, for the most part, composed of persons who are not specialists in monetary policy, one may suppose that the conclusions it arrived at emanated largely from the staff and the advisory board. Here and there the Report makes reference to shreds of new evidence, but - and I found this annoying - in no case was the precise nature or source of this evidence disclosed.

After expressing general confidence in the effectiveness of monetary policy, the Report goes on to recognize that, except in the area of residential construction, firm evidence of its effects is quite limited. As a consequence, the Report places considerable emphasis on the influence of monetary policy working through changes in the availability of credit and through changes in attitudes and expectations and on secondary interindustry and macro effects. The Commission's proposals for strengthening monetary policy include abandonment of the "bills only" policy, some streamlining of the admin- 
istrative apparatus of the Federal Reserve, suggestions that VA and FHA mortgage credit terms be varied countercyclically, and that the government investigate the possibility of devising selective controls in the fields of inventory investment and business plant and equipment expenditures. In contrast to the rather bold attitude adopted by the Commission in the field of fiscal policy, no very startling departures from the status quo were recommended for monetary policy.

Unfortunately, I have not seen all the research papers prepared for the use of the Commission that relate to problems of monetary policy, and I have not yet had sufficient time to study thoroughly all those I have seen. It is my general impression, however, that most of the papers do not provide a great deal of new evidence concerning the effects produced by monetary controls. One reason for this is that many of the papers were not intended to break new ground but merely to summarize the existing state of knowledge. Presumably, the Commission took the view that path-breaking new research on the effects of monetary policy would not be especially helpful, given the time limitations under which it was operating. Of necessity, a number of papers had to be commissioned on subjects related to the tools and mechanics of monetary policy. In addition, summaries of existing knowledge were prepared relating to the determinants of consumption expenditures, plant and equipment outlays, residential construction, and so on. These papers are, in general, well done and are of considerable value. However, since, up to now, there has been little success in isolating the effects of interest rates or other monetary variables, the contributions of these studies to the Commission's appraisal of monetary policy were for the most part quite negative.

Some of the research papers do, however, attempt to break new ground concerning the effects of monetary policy. On the theoretical side, there is a notable contribution by Tobin which presents a unified approach to questions of monetary policy and debt management focused around portfolio adjustments of investors. ${ }^{1}$ Of the empirical studies I have seen, the

\footnotetext{
${ }^{1}$ James Tobin, "An Essay on the Principles of Debt Management," preliminary version, 1960.
}

two that present new evidence most relevant to the assessment of the effectiveness of monetary policy are a study of lags by Brown, Solow, Ando, and Kareken, ${ }^{2}$ and a quantitative study of the effects of monetary and debt operations on interest rates by Okun. ${ }^{3}$

The Brown, Solow, Ando, and Kareken study breaks down the lag in monetary policy as follows: (I) the "inside" lag between the need for action and the Federal Reserve's response; (2) the lag between action by the Federal Reserve and the effect on interest rates and credit terms experienced by private spending units; and (3) the "outside" lag between changes in interest rates and credit terms and the effect on real output. The most notable contribution of the study lies in the effort to estimate the outside lag. The study deals separately with fixed investment in nonelectrical machinery and with inventory investment. ${ }^{4}$

The study of fixed investment uses new orders for nonelectrical machinery as the decision variable that is influenced by interest rates that is, the model is based on the rationale that interest rates affect orders with a lag and that production is adjusted to orders with a further lag. Several types of distributed lags having different time patterns are tried out, and new orders are found to depend on the index of industrial production, corporate profits, and the industrial bond yield. The interest elasticity of investment (at the point of means) is found to be about -.4 to -.5 . However, the effects are somewhat stretched out in time, with about 45 per cent occurring in the quarter in which a change in interest rates takes place, 25 per cent in the next quarter, and around 15 per cent in the third quarter - thus, about 85 per cent of the total effect occurs within three quarters or so.

To the lag between changes in interest rates and changes in orders must be added the lag between changes in orders and changes in production. Again using a relationship containing

\footnotetext{
${ }^{2}$ E. Cary Brown, Robert M. Solow, Albert Ando, and John H. Kareken, "Lags in Fiscal and Monetary Policy," preliminary version.

${ }^{3}$ Arthur M. Okun, Monetary Policy, Debt Management and Interest Rates: $A$ Quantitative Appraisal, Cowles Foundation Discussion Paper 125, June 21, 196r.

'The study also deals with the lags in fiscal policy.
} 
a distributed lag, the conclusions are roughly that 17 per cent of the effect of a change in orders is reflected in production of machinery within three months, 30 per cent within six months, and about 50 per cent within the first year.

While these results are somewhat tentative, they do strongly suggest ( $I$ ) that the ultimate effect of a change in the long-term interest rate on fixed investment may be quite substantial, but (2) that these effects are spread out over a considerable period of time, thereby creating a troublesome problem of timing for the monetary authorities.

With regard to inventory investment, the study employs a modified inventory accelerator type of equation and indicates that the elasticity of demand for inventories (total accumulated change in stock) with respect to the average interest rate on short-term bank loans is about -.4. However, there is again a distributed lag involved, with the result that about one-quarter of the total inventory investment will take place within one quarter after the change in the interest rate, about two-thirds by the end of four quarters, and about nine-tenths by the end of eight quarters. This again suggests serious problems of timing in using monetary policy to control inventory investment.

The Brown, et al., study has some shortcomings, and the authors are careful to emphasize the tentative nature of their findings. In the case of fixed investment, the difficulties include: failure to take account of supply conditions in the capital goods industry, which would surely condition the response of production to a change in interest rates; and inability to make allowance for the fact that the lags involved will vary with the state of expectations and the stock of inventories held by capital goods producers. But since the lags in the effects of monetary policy and the size of the responses that occur are very important and interrelated matters, this study is representative of the type of work that needs to be done if our knowledge of the working of monetary policy is to be significantly increased. In addition to further extension of this work on plant and equipment and inventory investment, similar studies are needed in other areas, such as residential construc- tion, and state and local government expenditures.

Okun's study is a quarterly analysis which attempts to estimate the effects of various monetary and debt operations on the short-term interest rate (Treasury bill rate) and the longterm interest rate (yield on long-term Treasury bonds). The analysis is so formulated as to permit quantitative estimates of the effects on the two interest rates that would result from open market operations in debt of various maturities, changes in reserve requirements, changes in the Federal Reserve discount rate, changes in the level of income, and operations by the Treasury or Federal Reserve that change the maturity composition of the publicly-held debt.

The most striking conclusion of the Okun study is that debt management operations which change the maturity composition of a given debt have very weak effects. Several alternative sets of equations are presented, but a typical conclusion is that the retirement of $\$ \mathrm{r}$ billion of Treasury bills and the simultaneous issuance of $\$ \mathrm{r}$ billion of 20 -year bonds will lower the bill rate by about two basis points and raise the long-term rate by less than one basis point. In general, the study suggests that the maturity structure of interest rates is primarily determined by the interest rate expectations of private lenders and borrowers and is not very sensitive to changes in the relative supplies of debt of different maturities - a conclusion that accords well with the results of other recent work on the determinants of the interest rate structure, such as that of David Meiselman. As Okun points out, his study suggests that the issue of "bills only" was not nearly so important as many of us thought it to be.

In addition to its implications with respect to the interest rate structure, the Okun study also indicates that rather large monetary operations are needed to produce substantial changes in the level of interest rates. For instance, a typical result is that open market sales of bills, notes, or other short-term issues in the amount of some $\$ 6$ billion will be needed to raise the long-term interest rate by 50 basis points. Nearly the same volume of sales of 20-year bonds would be needed to produce the same 
result. The conclusion seems to be, as Okun means the last word on their respective topics. points out, that vigorous action is necessary if However, they do seem to me to typify the kind monetary policy is to accomplish much. of quantitative research that is necessary if

The studies by Brown, Solow, Ando, and Kareken and by Okun are certainly by no our understanding of monetary phenomena is to be significantly improved. 